\title{
OPTIMIZATION OF PROCESS PARAMETERS FOR ENHANCED MECHANICAL PROPERTIES OF POLYPROPYLENE TERNARY NANOCOMPOSITES
}

\author{
Oladipupo Olaosebikan Ogunleye', Taofeeq Olalekan Salawudeen', \\ Muyibi A. Suleyman², Yusof Faridah² \\ 1 Department of Chemical Engineering, Faculty of Engineering and Technology, Ladoke Akintola University of \\ Technology, P.M.B. 4000, Ogbomoso, Nigeria, e-mail: ooogunleye@yahoo.com \\ 2 Department of Biotechnology Engineering, Kulliyyah of Engineering, International Islamic University \\ Malaysia, Jalan Gombak, Kuala Lumpur, Malaysia
}

Received: 2015.02.05

Accepted: 2015.02.14

Published: 2015.03.01

\begin{abstract}
Preparation of Polypropylene ternary nanocomposites (PPTN) was accomplished by blending multiwall carbon nanotube (MWCNT) in polypropylene/clay binary system using a melt intercalation method. The effects of MWCNT loadings (A), melting temperature (B) and mixing speed (C) were investigated and optimized using central composite design. The analysis of the fitted cubic model clearly indicated that A and B were the main factors influencing the tensile properties at a fixed value of $\mathrm{C}$. However, the analysis of variance showed that the interactions between the process parameters, such as; $\mathrm{AB}, \mathrm{AC}, \mathrm{AB}^{2}, \mathrm{~A}^{2} \mathrm{~B}$ and $\mathrm{ABC}$, were highly significant on both tensile strength and Young's modulus enhancement, while no interaction is significant in all models considered for elongation. The established optimal conditions gave $0.17 \%, 165{ }^{\circ} \mathrm{C}$, and $120 \mathrm{rpm}$ for A, B and C, respectively. These conditions yielded a percentage increase of 57 and $63 \%$ for tensile strength and Young's modulus respectively compared to the virgin Polypropylene used.
\end{abstract}

Keywords: MWCNT, PPTN, tensile strength and Young's modulus.

\section{INTRODUCTION}

Polypropylene is an important plastic, which offers probably the best quality among polyolefins at low cost $[1,2]$. It has a wider area of applications, such as packaging, home utensils, casings and automobile accessories compared than any other thermoplastic. In addition, polypropylene has a lower density between 900 and $920 \mathrm{~kg} / \mathrm{m}^{3}$, in comparison to other engineering materials, allowing for potential weight reductions, very good heat resistance and due to its higher crystallinity, it is an excellent moisture barrier and has good optical properties [3, 4].

Polymers in their pure and natural state are either reinforced with organic fillers, such as sisal, flax, jute and wood fibres [5, 6], or particulate fillers, such as tack, $\mathrm{CaCO}_{3}$ and mica. Such polymer composites are credited with better proper- ties relative to their parent matrix and have found a wide array of applications in the civil construction industries $[7,8]$. They are term microcomposite simply because the fillers are dispersed in micro scale. However, effort in the field of polymer microcomposite has reached the highest level of optimization because most times higher filler loading is usually required and consequently affect the final material.

Research on polymer nanocomposites became subject of interest since the successful preparation and application of $\mathrm{PA} /$ montmorillonite composites by Toyota over a decade ago. Such nanocomposites prepared from PA 6 possessed good mechanical and thermal properties at low filler loading and, therefore, provided a better economical solution in various fields of application [9]. Various studies reported improvement in mechanical $[10,11]$, thermal and flammability 
$[12,13]$, and barrier $[14,15]$ properties of thermoplastic by addition of organically modified layered silicates to polymer matrices. This has attracted further studies in the field of polymeric composite.

Polypropylene, among thermoplastic has a wider area of industrial applications. It can be modified in many ways and its fibre reinforced grades compete even with most engineering polymers. Consequently, many attempts have been made to prepare polypropylene-layered silicate nanocomposite (PP/MNC) in order to have a material of better properties compared to the conventional polymer micro-composite. However, practically all composites prepared from organophilic clay and polypropylene do not show improvements in an extent that satisfies the requirements of most applications in terms of mechanical properties because complete dispersion of the silicate is never achieved in the PP matrix [16]. In addition, the achieved properties usually differ from the intended trade-off what affects the quality of the final composite. As a result, effort is ongoing to produce composite that will combine more than one filler in a polymer matrix. Such that there will be shared properties and shortcomings from one filler can be addressed by the other called a secondary filler [14, 17]. Carbon nanotube is suggested in this study as a secondary filler due to its special intrinsic properties and high aspect ratio combined with surface area.

Due to the complexity in the behavior of Polypropylene blend with nanomaterials cum their reaction towards process parameters such as melting temperature, mixing speed and filler loadings, optimization of the process parameters is rarely reported. The present work is therefore aimed at optimizing these process parameters to enhance the properties of PPTN. Such ternary combination will address the most common shortcomings, such as low mechanical properties and trade-off problems peculiar to the binary precursor ( $\mathrm{PP} /$ $\mathrm{MNC}$ ) and hence possess better properties.

\section{METHODOLOGY}

\section{Materials}

Multiwall carbon nanotubes with outer diameter range between $10 \mathrm{~nm}$ and $20 \mathrm{~nm}$, length $\sim 30 \mu \mathrm{m}$ and $95 \%$ purity was manufactured by Zyvex Instrument, Germany and supplied by Cahaya BHD SDN, Malaysia. Bentonite clay manufactured by
Across Organics was modified in the laboratory using octadecylamine salt. Polypropylene homopolymer with an MFR $>3 \mathrm{~g} / 10 \mathrm{~min}$ manufactured by Petronas Malaysia was used as matrix, while maleic anhydride grafted polypropylene (PPgMA oligoma) (Polybond 3200) with $1.2 \mathrm{wt} \%$ MA was used as compatibilizer.

\section{Selection of range of process parameters}

Range of the selected process parameters was determined by using design expert version 6.0.8, Stat-ease Inc, USA with full factorial, three factors with low and high levels: The selected parameters were varied between 170 and $250^{\circ} \mathrm{C}$ for melting temperature, 0.1 to $1 \%$ of binary precursor for MWCNT loading and 100 to $200 \mathrm{rpm}$ for mixing speed. These were used in the preparation of ternary nanocomposite according to Table 1 below, the final PPTN were tested for their tensile properties using ASTM D638, and the results were analyzed.

Table 1. Experimental design for determination of range for process parameters

\begin{tabular}{|c|c|c|c|}
\hline $\begin{array}{c}\text { Experimental } \\
\text { run }\end{array}$ & $\begin{array}{c}\text { Carbon } \\
\text { nanotube (\%) }\end{array}$ & $\begin{array}{c}\text { Mixing } \\
\text { speed }(\mathrm{rpm})\end{array}$ & $\begin{array}{c}\text { Melting } \\
\text { temperature }\left({ }^{\circ} \mathrm{C}\right)\end{array}$ \\
\hline 1 & 0.1 & 200 & 250 \\
\hline 2 & 1 & 50 & 170 \\
\hline 3 & 1 & 200 & 170 \\
\hline 4 & 1 & 50 & 250 \\
\hline 5 & 0.1 & 200 & 170 \\
\hline 6 & 0.1 & 50 & 250 \\
\hline 7 & 1 & 200 & 250 \\
\hline 8 & 0.1 & 50 & 170 \\
\hline
\end{tabular}

\section{Preparation of PP-Clay/MWCNTs nanocomposites}

Ternary nanocomposite production was carried out using melt-mixing method in a hakee mixer (Type Rheomix 600P) by employing a twobatch system. First batch involved the production of Polypropylene/Clay binary precursor using $3 \%$ layered silicate in the presence of MAgPP as compatibilizer. The second batch system involved the introduction of MWCNT according to experimental design (Table 2). The final nanocomposite was pelletized, hot pressed and molded into standard shape according to ASTM D638. The molded plaque was then subjected to mechanical test using universal tensile machine (LYLOYD Instruments, Type 1025). 


\section{Experimental design}

Optimization using central composite design (CCD) of the response surface (RSM) is a suitable tool for determination of optimum conditions when many factors affect a desired response [18]. In this work, seventeen experiments were carried out according to the conditions indicated in Table 2. The response values (tensile strength, Young modulus and elongation) are reported in the last three columns of the table.

\section{RESULTS AND DISCUSSION}

\section{Range of process parameters using factorial design}

The tensile properties of the selected process parameters based on high and low level of values are shown on Table 3. This consideration shows the effect of low and high value of the selected parameters on the tensile properties and hence gave the required range of values for the optimization purpose. The results were analyzed by grouping the experimental blocks into a pair of similar parameters (for example mixing speed and MWCNT loading) and the third parameter (melting temperature) varied. Similarly, melting temperature and MWCNT were fixed and the mixing speed was varied. The analysis of the results showed that the tensile strength of the composite produced at $250^{\circ} \mathrm{C}$ melting temperature was lower than that at $170{ }^{\circ} \mathrm{C}$ for a fixed MWCNT loading and mixing speed. The tensile properties at $170{ }^{\circ} \mathrm{C}$ were in the range of 30 to $32 \mathrm{MPa}$, for tensile strength and between 1200 and $1700 \mathrm{MPa}$ for Young's modulus while at $250{ }^{\circ} \mathrm{C}$, the properties lied between the range of 20 and $25 \mathrm{MPa}$ tensile strength and 1000 and $1300 \mathrm{MPa}$ Young's modulus respectively. The loss in the tensile properties at higher temperature could be traced to the degeneration in the plastic properties of PP, which resulted in low viscosity, and hence loss of binding effect on the fillers within the matrix. This agrees with the Eisten postulate, equation (1) which states that the effect of filler on modulus is proportional to that on viscosity.

$$
\eta=\eta_{s}\left(1+2.5 V_{r}\right)
$$

Where $\eta$ represents the viscosity of the composite, $\eta_{s}$ represents the viscosity of the matrix and $V_{r}$ the filler volume fraction. When the viscosity terms in equation (1) is replaced by the modulus term $E$, the equation gives:

$$
E=E_{s}\left(1+2.5 V_{r}\right)
$$

$E$ and $E_{s}$ represent the modulus for composite and matrix respectively. Therefore, at $250{ }^{\circ} \mathrm{C}$ melting temperature, an irreversible drop in viscosity of the nanocomposites can be explained in terms of the drop in the stiffness measured as a function of Young's modulus.

\begin{tabular}{|c|c|c|c|c|c|c|}
\hline Run & $\begin{array}{c}\text { Factor A } \\
\text { CNT } \\
(\%) \\
\end{array}$ & $\begin{array}{c}\text { Factor B } \\
\text { Temperature } \\
\left({ }^{\circ} \mathrm{C}\right) \\
\end{array}$ & $\begin{array}{c}\text { Factor C } \\
\text { Mixing speed } \\
(\mathrm{rpm}) \\
\end{array}$ & $\begin{array}{c}\text { Response } 1 \\
\text { Tensile strength } \\
(\mathrm{MPa}) \\
\end{array}$ & $\begin{array}{c}\text { Response } 2 \\
\text { Young's modulus } \\
(\mathrm{MPa})\end{array}$ & $\begin{array}{c}\text { Response } 3 \\
\text { Elongation } \\
(\%) \\
\end{array}$ \\
\hline 1 & 0.45 & 190 & 125 & 35.60 & 1847 & 8.30 \\
\hline 2 & 0.8 & 170 & 125 & 50.26 & 1797 & 13.76 \\
\hline 3 & 0.8 & 190 & 100 & 38.42 & 1735 & 9.70 \\
\hline 4 & 0.1 & 190 & 100 & 34.53 & 1821 & 9.13 \\
\hline 5 & 0.45 & 170 & 150 & 48.72 & 1634 & 11.36 \\
\hline 6 & 0.1 & 150 & 150 & 52.30 & 1641 & 16.08 \\
\hline 7 & 0.45 & 170 & 125 & 49.37 & 1725 & 13.35 \\
\hline 8 & 0.1 & 170 & 125 & 51.37 & 1821 & 13.85 \\
\hline 9 & 0.8 & 150 & 100 & 45.42 & 1849 & 11.07 \\
\hline 10 & 0.45 & 150 & 125 & 47.78 & 1677 & 6.00 \\
\hline 11 & 0.1 & 190 & 150 & 30.14 & 1725 & 7.43 \\
\hline 12 & 0.45 & 170 & 125 & 49.37 & 1725 & 13.35 \\
\hline 13 & 0.8 & 150 & 150 & 50.96 & 1663 & 14.94 \\
\hline 14 & 0.45 & 170 & 100 & 47.11 & 1600 & 12.52 \\
\hline 15 & 0.1 & 150 & 100 & 50.79 & 1780 & 14.77 \\
\hline 16 & 0.45 & 170 & 125 & 49.37 & 1725 & 13.35 \\
\hline 17 & 0.8 & 190 & 150 & 50.26 & 1797 & 13.76 \\
\hline
\end{tabular}

Table 2. Central composite design for PP/Clay/CNT and responses 
The effect of shear was measured in terms of mixing speed. Therefore, at a fixed melting temperature and percentage MWCNT, the results show that tensile properties increase with shear but the rate of increase was not so significant. For example in the case of composites produced at a fixed temperature of $170{ }^{\circ} \mathrm{C}$ and $0.1 \% \mathrm{CNT}$ loading (EH); the tensile strength was $31.27 \mathrm{MPa}$ and $31.58 \mathrm{MPa}$ at 100 and $200 \mathrm{rpm}$ respectively and $1259.12 \& 1209.06 \mathrm{MPa}$ for Young's modulus respectively. The same explanation holds for other combinations such as; $\mathrm{BC}, \mathrm{AF}$ and DG. It is therefore concluded that melting temperature and CNTs loadings have more significant effect on the preparation of PPTN compared to mixing speed.

Also when the filler loading was varied while the melting temperature and mixing speed kept constant (such as: AG, BH, CE and DE). Considering a pair AG, Table 3 shows that at a fixed melting temperature of $250{ }^{\circ} \mathrm{C}$ and mixing speed of $200 \mathrm{rpm}$, the tensile strengths at 0.1 and $1 \%$ MWCNT were 25.1 and $22.73 \mathrm{MPa}$ while the Young's modulus 1513.48 and $1280.40 \mathrm{MPa}$ respectively. This shows that at $1 \%$ MWCNT loading, the tensile properties are affected traceable to the formation of agglomerates in the polymer matrices. Specifically on the PPTN; increase in CNT may saturate the PP/Clay binary precursor due to the existing filler (layered silicate) in the matrix, thereby increased the rate of formation of agglomerates and hence reducing the tensile properties. Sometimes, Young's modulus may be favored by increasing filler loading but usually at the expense of other properties, such situation was observed in $\mathrm{BH}$ where the Young's modulus of the composite sample was 1259.12 MPa at 0.1\% CNT and 1621.64 MPa at $1 \%$ CNT. Further increase in CNT might lead to a complete loss in both the tensile strength and the Young's modulus.

\section{Test of significance and accuracy of the model}

The level of significance and accuracy of the fitted models were tested through the analysis of variance using p-value. As shown in Table 4, it is evident from ANOVA that the third order polynomial model for both the tensile strength and Young's modulus are highly significant with $\mathrm{p}$-value of 0.0018 and 0.0002 respectively knowing fully well that for $p$-value $<0.05$, the model terms are significant and for $\mathrm{p}$-value $<0.01$, the model terms are highly significant [19]. However, the model terms for the elongation are not significant due to its high p-value (0.2598). This result is also justified from the experimental data, which showed an inconsistency pattern for the elongation.

Following the above arguments, it is evident from Table 4 that the variables that are highly significant are $\mathrm{B}, \mathrm{B}^{2}, \mathrm{AB}$ and $\mathrm{AC}$ while $\mathrm{A}^{2} \mathrm{AB}^{2}$ and $\mathrm{ABC}$ are significant factors in the case of tensile strength where A represents the MWCNTs loading (\%), B represents the temperature $\left({ }^{\circ} \mathrm{C}\right)$ and $\mathrm{C}$ the mixing speed (rpm). In the case of Young's modulus (Table 6), the highly significant factors are; $\mathrm{B}, \mathrm{A}^{2}, \mathrm{~B}^{2}, \mathrm{C}^{2}, \mathrm{AB}, \mathrm{AC}, \mathrm{BC}, \mathrm{A}^{2} \mathrm{~B}, \mathrm{~A}^{2} \mathrm{C}, \mathrm{AB}^{2}$ and $A B C$ while only $A$ is significant. From the above analysis both linear and polynomial effects of parameters were significant, meaning that they can act as limiting factor and little variation in their values can alter the properties (Tensile strength and Young's modulus) of the composite. Considering the third model (Elongation), no significant factor was recorded either in the linear or polynomial model (Table 4). This implies that the addition of CNT though enhanced other properties, but did not have any significant effect on elongation. It can therefore be inferred from the analysis of results that Table 4 are true a representation of the model and can be used to determine the responses of the composite to changes in the

Table 3. Tensile properties of PPTN for determination of range for process parameters

\begin{tabular}{|c|c|c|c|c|c|}
\hline $\begin{array}{c}\text { Sample } \\
\text { PP/Clay/CNTs }\end{array}$ & $\begin{array}{c}\text { Melting } \\
\text { temperature }\left({ }^{\circ} \mathrm{C}\right)\end{array}$ & $\begin{array}{c}\text { Mixing speed } \\
(\mathrm{rpm})\end{array}$ & $\begin{array}{c}\text { CNTs loading } \\
(\%)\end{array}$ & $\begin{array}{c}\text { Tensile strength } \\
(\mathrm{MPa})\end{array}$ & $\begin{array}{c}\text { Young's modulus } \\
(\mathrm{MPa})\end{array}$ \\
\hline $\mathrm{A}$ & 250 & 200 & 0.1 & 25.1 & 1513.48 \\
\hline $\mathrm{E}$ & 170 & 200 & 0.1 & 31.58 & 1209.06 \\
\hline F & 250 & 100 & 0.1 & 26.11 & 1121.80 \\
\hline H & 170 & 100 & 0.1 & 31.27 & 1259.12 \\
\hline B & 170 & 100 & 1.0 & 26.45 & 1621.64 \\
\hline D & 250 & 100 & 1.0 & 23.53 & 1264.18 \\
\hline C & 170 & 200 & 1.0 & 31.15 & 1375.24 \\
\hline G & 250 & 200 & 1.0 & 22.73 & 1280.40 \\
\hline
\end{tabular}


Table 4. Summary of statistical analysis using ANOVA

\begin{tabular}{|c|c|c|c|}
\hline \multirow{2}{*}{$\begin{array}{l}\text { Statistical } \\
\text { analysis }\end{array}$} & \multicolumn{3}{|c|}{$p$-value } \\
\hline & $\begin{array}{c}\text { Tensile } \\
\text { strength }\end{array}$ & $\begin{array}{l}\text { Young's } \\
\text { modulus }\end{array}$ & Elongation \\
\hline Model & 0.0018 & 0.0002 & 0.2598 \\
\hline A & 0.4097 & 0.0324 & 0.9782 \\
\hline B & 0.0018 & 0.0001 & 0.4741 \\
\hline C & 0.2584 & 0.0127 & 0.7093 \\
\hline$A^{2}$ & 0.0171 & $<0.0001$ & 0.1055 \\
\hline $\mathrm{B}^{2}$ & 0.0009 & 0.0006 & 0.0499 \\
\hline $\mathrm{C}^{2}$ & 0.3937 & $<0.0001$ & 0.5025 \\
\hline$A B$ & 0.0009 & 0.0037 & 0.1283 \\
\hline$A C$ & 0.0031 & 0.0032 & 0.2356 \\
\hline $\mathrm{BC}$ & 0.8682 & 0.0002 & 0.6511 \\
\hline$A^{2} B$ & 0.6451 & 0.0003 & 0.1304 \\
\hline $\mathrm{A}^{2} \mathrm{C}$ & 0.2164 & 0.0004 & 0.4054 \\
\hline $\mathrm{AB}^{2}$ & 0.0246 & 0.0089 & 0.861 \\
\hline$A B C$ & 0.0133 & 0.0005 & 0.6069 \\
\hline
\end{tabular}

$\mathrm{p}<0.05$ indicate the model terms are significant.

$\mathrm{p}<0.01$ indicate the model terms are highly significant

process parameters. However, if elongation is of prime importance in the application of nanocomposite, the plasticizer, mostly phthalate esters, can be added in a predetermined quantity.

To further reaffirm the significance of the fitted model using regression analysis, the coefficients of determinations (actual $\mathrm{R}^{2}$ and adjusted $\mathrm{R}^{2}$ ) were computed and compared. This is because $\mathrm{R}^{2}$ only measures the amount of reduction in the variability obtained by using the regressor variables [20]. However, a large value of $\mathrm{R}^{2}$ does not necessarily imply that the regression model is a good one and as a result, adjusted $\mathrm{R}^{2}$ were computed and compared with actual $\mathrm{R}^{2}$ to justify the significance of the model. Table 5 shows that the coefficient of determination $\mathrm{R}^{2}$ and adjusted $\mathrm{R}^{2}$ for both the tensile strength and Young's modulus are near to 1 which implies that the regression models are highly significant. In comparison with elongation, though $\mathrm{R}^{2}$ of $91 \%$ is large enough but when compared with adjusted $\mathrm{R}^{2}(52 \%)$, there is a wide gap. This also justifies the anomalous behavior of elongation. Adequate precision measures the signal to noise ratio $(\mathrm{S} / \mathrm{N})$. A ratio greater than 4 is desirable [19]. Hence adequate precission for both tensile strength and Young modulus $(\approx 30$ and 60 ) are large enough for the significancy of the model. However, the adequate precission for elongation of 4.8 is just adequate but less significant or practically insignificant. This also is in agreement with other observation made so far in this research.
Table 5. Measure of significance using $\mathrm{R}^{2}$ and adequate precision

\begin{tabular}{|l|c|c|c|}
\hline \multicolumn{1}{|c|}{$\begin{array}{c}\text { Statistical } \\
\text { tool }\end{array}$} & $\begin{array}{c}\text { Tensile } \\
\text { strength }\end{array}$ & $\begin{array}{c}\text { Young's } \\
\text { modulus }\end{array}$ & Elongation \\
\hline R-squared & 0.9973 & 0.9994 & 0.9112 \\
\hline Adj R-squared & 0.9857 & 0.9966 & 0.5265 \\
\hline Adq. precision & 29.868 & 60.624 & 4.892 \\
\hline
\end{tabular}

\section{Model equations}

In order to predict the optimal regions for the production of ternary nanocomposite considering the three responses [tensile strength $(\mathrm{T} / \mathrm{S})$, Young's modulus $(\mathrm{Y} / \mathrm{M})$ and elongation (E)] within the experimental constraints: CNT loadings (A), melting temperature (B) and mixing speed (C). A third order polynomial model was fitted to the experimental results using the Design Expert software and the following models were developed for each of the responses.

Model equations in terms of actual factors:

$\mathrm{T} / \mathrm{S}=-627+430 \mathrm{~A}+7.23 \mathrm{~B}+1.79 \mathrm{C}+57.12 \mathrm{~A}^{2}-$ $0.02 \mathrm{~B}^{2}-4.35 \mathrm{AB}-2.49 \mathrm{AC}-0.01 \mathrm{BC}-0.25 \mathrm{~A}^{2} \mathrm{C}$ $+6.72 \mathrm{E}-003 \mathrm{AB}^{2}+0.02 \mathrm{ABC}$

$\mathrm{Y} / \mathrm{Mod}=531+1776 \mathrm{~A}+3 \mathrm{~B}+24 \mathrm{C}+8487 \mathrm{~A}^{2}-$ $0.06 \mathrm{~B}^{2}-0.18 \mathrm{C}^{2}-76.27 \mathrm{AB}+8 \mathrm{AC}+0.11 \mathrm{BC}$ $-36.83^{2} \mathrm{~B}-12.57 \mathrm{~A}^{2} \mathrm{C}+0.32 \mathrm{AB}^{2}+0.01 \mathrm{ABC}$

Elong $=-249-122.23 \mathrm{~A}+3.33 \mathrm{~B}+0.09 \mathrm{C}+179.42 \mathrm{~A}^{2}$ $-9.47 \mathrm{E}-003 \mathrm{~B}^{2}+1.65 \mathrm{E}-003 \mathrm{C}^{2}+0.72 \mathrm{AB}-$ $0.87 \mathrm{AC}-3.01 \mathrm{E}-003 \mathrm{C}-1.21 \mathrm{~A}^{2} \mathrm{~B}+0.40 \mathrm{~A}^{2} \mathrm{C}$ $+1.50 \mathrm{E}-004 \mathrm{AB}^{2}+3.895 \mathrm{E}-003 \mathrm{ABC}$

Following the model equations above, it can be inferred that equation 3 to 5 are better combinations and can be used for the determination of the required process parameters for the production of PP-ternary nanocomposites of a known tensile properties.

\section{Condition for optimum responses}

The relationship between the responses and the experimental variables are illustrated graphically by plotting three-dimensional (3D) response surface graphs (Figures 1 to 3 ). The $y$-axis represents any of the responses (T/S, Y/M or E) while $x$ and $z$-axes represent any two of the three independent variables. In this case, $x$ and $y$ are melting temperature and MWCNT percentage respectively, while mixing speed was fixed at $125 \mathrm{rpm}$. In Figure 1 examination of three-dimensional plot showed that the tensile strength is in the optimum 


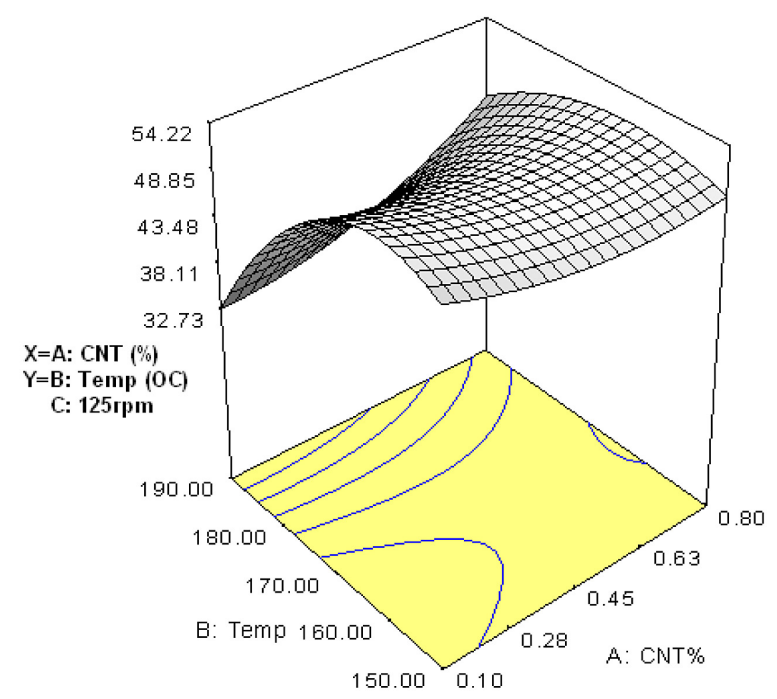

Fig. 1. Response surface plots showing the effect of temperature and MWCNT loadings on the tensile strength of PPTN

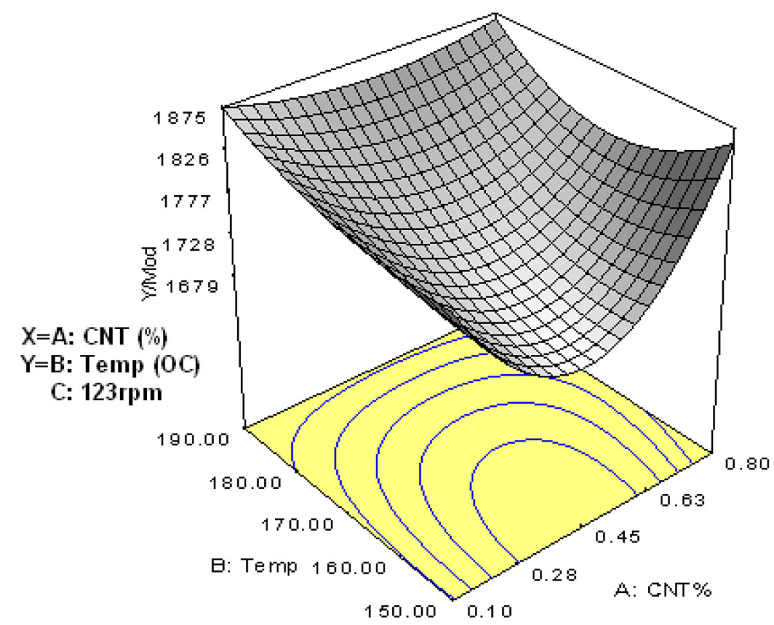

Fig. 2. Response surface plots showing the effect of temperature and MWCNT loadings on the Young's modulus of PPTN

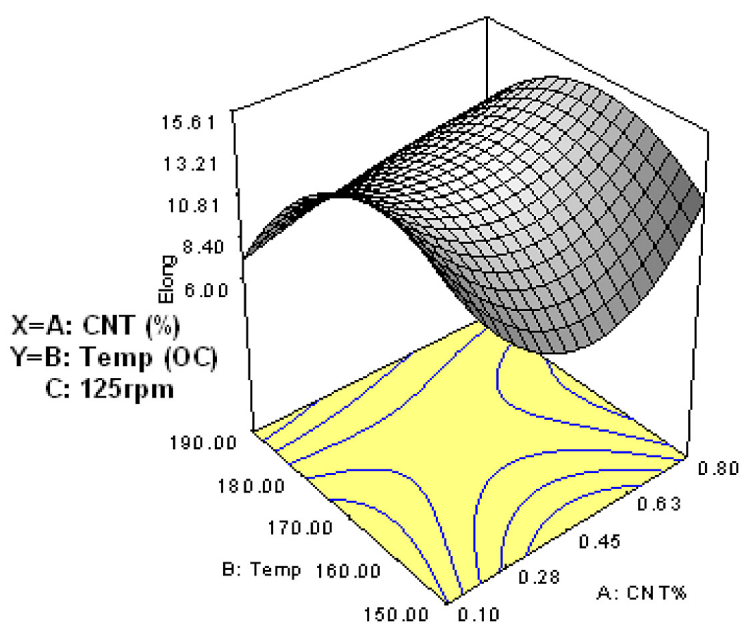

Fig. 3. Response surface plots showing the effect of temperature and MWCNT loadings on the elongation of PPTN region when the temperature lies between 150 and $170{ }^{\circ} \mathrm{C}$ and MWCNT loadings is between 0.1 and $0.28 \%$.

However, if the targeted property is Young's modulus, Figure 2 showed that the optima region also lies between 150 and $170{ }^{\circ} \mathrm{C}$ while the CNT loadings lies between 0.28 and $0.63 \%$. Generally, this implies that for the production of PPternary nanocomposite with high tensile strength and Young's modulus as the targeted properties, the favorable temperature is between $150{ }^{\circ} \mathrm{C}$ and $170{ }^{\circ} \mathrm{C}$ and the MWCNT loading is between 0.1 and $0.6 \%$ considering Figure 1 and 2 .

Regarding the elongation, no consistent pattern could be established statistically for the effect of the process parameters due to low predicted $\mathrm{R}^{2}$, high $\mathrm{p}$-value and low adequate precision however, some general trends which agreed with the predicted optimal regions such as melting temperature of 150 to $170^{\circ} \mathrm{C}$ and 0.28 to 0.63 MWCNT loading are indicated in the response surface curve as shown in Figure 3.

\section{Validation of the model}

In order to justify the optimization results obtained in Figure 1, 2 and 3, and to determine the exact optimum point a set of supplementary experiments were carried out based on the suggested optima conditions. The results are as shown in Table 6.

The highest tensile properties were obtained at optimum conditions, which are when the MWCNT content was $0.17 \%$, melting temperature of $165.45^{\circ} \mathrm{C}$ and mixing speed of $119.11 \mathrm{rpm}$. This is also justified from the surface response plots (Figures 1 and 2) where the optimum region lies between 0.1 and $0.28 \%$ MWCNT for the tensile strength and between 0.28 and $0.63 \%$ MWCNT for the Young's modulus. The optimum temperature lies generally between 150 and $170{ }^{\circ} \mathrm{C}$.

\section{CONCLUSIONS}

In this study, ternary nanocomposites of Polypropylene, which comprises of modified nanoclay and multiwall carbon nanotubes have been prepared, characterized and the operating parameters optimized. The three key process parameters considered are MWCNT loadings, melting temperature and the mixing speed and the major responses were tensile strength, Young's modulus and elongation. This study clearly developed 
Table 6. Validation of the developed model

\begin{tabular}{|c|c|c|c|c|c|c|c|}
\hline \multirow{2}{*}{ NO } & \multicolumn{3}{|c|}{ Process Parameters } & \multicolumn{3}{c|}{ Predicted } & \multicolumn{2}{c|}{ Experimental } \\
\cline { 2 - 8 } & CNT (\%) & Temp. (OC) & M/S (rpm) & T/S & Y/M & T/S & Y/M \\
\hline 1 & 0.17 & 165.45 & 119.11 & 51.98 & 1757 & 52.30 & 1759.32 \\
\hline 2 & 0.45 & 151.31 & 121.16 & 47.61 & 1677 & 48.19 & 1679.26 \\
\hline 3 & 0.61 & 153.03 & 121.47 & 47.96 & 1718 & 47.43 & 1726.14 \\
\hline
\end{tabular}

three statistical models that can be used to predict the operating parameters once the tensile properties are fixed for the production of PP-ternary nanocomposite. Hence, novel plastic materials of specific properties can be developed for various industrial applications.

\section{REFERENCES}

1. Mittal V. Polypropylene-layered silicate nanocomposites: Filler matrix interactions and mechanical properties. Journal of Thermoplastic Composite Materials, 20, 2007, 575-599.

2. Nello P. Polypropylene handbook. Second edition, Hanser Publishers, Munich, Hanser Gadner Publications, Cincinnati 2005, 326-334,

3. Karian H.G. Handbook of polypropylene and polypropylene composites. Marcel Dekker, NY. 2003, $155-158$.

4. Valentini L., Biagiott I.K., Kenny J.M. Lopez M., Manchando M.A. Physical and mechanical behaviour of single wall carbon nanotube/polypropylene/ethylene-polypropylene-diene rubber nanocomposite. Journal of Applied Polymer Science, 89(10), 2003, 2657-2663.

5. Hu N., Masuda Z., Yamamoto G., Fukunaga H., Hashida T., Qin J. Effect of fabrication process on electrical properties of polymer/ multi-wall carbon nanotube nanocomposites composites. Part A. Applied Science and Manufacturing, 39(5), 2008, 893-903.

6. Xun X., Krishnan J., Caroline M.,, Nicholas S. Life Cycle assessment of wood-fibre reinforced polypropylene composite. Journal of Material Processing Technology, 198, 2008, 168-177.

7. Ma J., Qi Z., Hu Y. Synthesis and characterization of polypropylene-clay nanocomposites. Journal of Applied Polymer Science, 82, 2001, 3611-3617.

8. Thostenson E.J., Ren Z., Chou T.W. Advances in science and technology of carbon nanotubes and their composites. A review. Composite Science and Technology, 61, 2001, 1899-1912.
9. Bafna A., Beaucage G., Mirabella F., Mehta S. 3D hierarchical orientation in polymer-clay nanocomposite film. Polymer, 44(4), 2003, 1103-1115.

10. Fornes T.D., Yoon P.J., Keskkula H., Paul D.R. Nylon 6 nanocomposites: The effect of matrix molecular weight. Polymer, 42(25), 2001, 9929-9940.

11. Oya A., Kurokawa Y., Yasuda H. Factors controlling mechanical properties of clay mineral/ polypropylene nanocomposites. Journal of Material Science, 35(5), 2000, 1045-1050.

12. Gilman J.W. Flammability and thermal stability studies of polymer layered-silicate (clay) nanocomposites. Applied Clay Science 15, 1999, 31-49.

13. Isam Y.Q. The potential of carbon nanotubes production as a filler element in polymer nanocomposite: A review article. Minia Journal of Engineering and Technology, 30(1), 2011, 1-21.

14. Chen T.K., Tien Y.I., Wei K.H. Synthesis and characterization of novel segmented polyurethane/clay nanocomposite. Polymer, 41(4), 2000, 1345-1353.

15. Sudip R., Siew Y.Q., Allan E., Xiao D.C. The potential use of polymer-clay nanocomposites in food packaging. International Journal of Food Engineering 2(4), 2006, 4-13.

16. Laszlo S., Agnes A., Pukanszky B.Jr., Julius G.V., Punkaszky B. Morphological characterization of $\mathrm{PP} /$ Clay nanocomposites across the length scales of the structural architecture. Micromolecular Materials and Engineering, 291(7), 2006, 858-868.

17. Salawudeen T.O., Suleyman A.M., Qasim H.S., Ma'an F.A., Faridah Y., Isam Y.Q. Improving the polypropylene-clay composite using carbon nanotube as secondary filler. Energy Research Journal 1 (2), 2010, 68-72.

18. Manel M, Souhail B., Moncef C., Christelle R., Michel P., Christophe B., Hamadi A. Optimization of pecting extraction from lemon by-product with acidified date juice using response surface methodology. Carbohydrate Polymers, 74, 2008, 185-192.

19. Stat-Ease, Design Expert, Version 6.0.8. Available on wwwstatease.com(2002).

20. Douglas C.M. Design and analysis of experiments. 5th edition. Wiley, NY, 2000, 388-424. 